OPEN ACCESS

Edited by:

Zhiyi Lv,

Ocean University of China, China

Reviewed by:

Marina Mapelli,

European Institute of Oncology (IEO),

Italy

Jorge Torres, UCLA Department of Chemistry and Biochemistry, United States

*Correspondence:

Dengwen Li

dwli@nankai.edu.cn

Specialty section:

This article was submitted to

Signaling,

a section of the journal

Frontiers in Cell and Developmental

Biology

Received: 14 July 2020 Accepted: 01 September 2020

Published: 17 September 2020

Citation:

Wu X, Zhou J and Li D (2020) Orientation of the Mitotic Spindle in Blood Vessel Development. Front. Cell Dev. Biol. 8:583325. doi: 10.3389/fcell.2020.583325

\section{Orientation of the Mitotic Spindle in Blood Vessel Development}

\author{
Xuemei $W u^{1}$, Jun Zhou ${ }^{1,2}$ and Dengwen $\mathrm{Li}^{1 *}$ \\ 1 State Key Laboratory of Medicinal Chemical Biology, College of Life Sciences, Nankai University, Tianjin, China, ${ }^{2}$ Shandong \\ Provincial Key Laboratory of Animal Resistance Biology, Collaborative Innovation Center of Cell Biology in Universities \\ of Shandong, College of Life Sciences, Institute of Biomedical Sciences, Shandong Normal University, Jinan, China
}

Angiogenesis requires coordinated endothelial cell specification, proliferation, and collective migration. The orientation of endothelial cell division is tightly regulated during the earliest stages of blood vessel formation in response to morphogenetic cues and the controlled orientation of the mitotic spindle. Consequently, oriented cell division is a vital mechanism in vessel morphogenesis, and defective spindle orientation can perturb the spatial arrangement of daughter cells and consequently contribute to several diseases related to vascular development. Many factors affect endothelial cell proliferation and orientation and therefore blood vessel formation, with the relationship between improper spindle orientation in endothelial cells and various diseases extensively studied. Here we review the molecular mechanisms driving the orientation of endothelial cell division, particularly with respect to the mitotic spindle, and how these processes affect vascular development, disease pathogenesis, and their potential as novel targets.

Keywords: spindle orientation, angiogenesis, mitotic spindle, cell proliferation, blood vessel development

\section{INTRODUCTION}

Blood vessel development, which includes vasculogenesis and angiogenesis, is crucial for the formation of the cardiovascular system and blood vessel regeneration after injury. The vasculature is one of the first organ systems to develop during vertebrate embryogenesis (Wilkinson and van Eeden, 2014). Angiogenesis is important in a number of pathophysiological processes (Sajib et al., 2018), not only supporting the developing embryo and in wound healing but also in many diseases including cancer, infectious arthritis, and psoriasis (Carmeliet, 2000; Sajib et al., 2018). The formation of the vascular plexus requires exquisite regulation and integration of several cellular processes: endothelial cells sprout in response to morphogenetic cues and must actively divide to expand the endothelial cell pool. As a consequence, abnormal blood vessel development contributes to numerous diseases such as cancer and intraocular vascular disorders (Apte et al., 2019), with aberrant endothelial cell proliferation, migration, polarity, and the maintenance of intercellular junctions central processes (Hogan and Schulte-Merker, 2017).

Spindle orientation determines the fate and position of daughter cells during mitosis (Li J. et al., 2019) and plays an important role in development, including epithelium and vascular endothelium development. Epithelium development plays a critical role in organ development and tissue repair (Ting Song, 2020), which requires proper orientation of the mitotic spindle (Xie and Zhou, 2017; Xie et al., 2017). In proliferating epithelium, planar cell division occurs by orienting mitotic spindles into the epithelial plane to ensure organized tissue formation (Luo et al., 2016; Nakajima, 2018). Asymmetric positioning of the mitotic spindle during endothelial tip cell division generates 
multicellular polarity, which drives coordinated and collective cell migration in angiogenesis (Costa et al., 2016). During asymmetric division, mitotic spindles must be placed on the polarization axis to ensure the correct orientation of daughter cells (Liro and Rose, 2016). In view of the direct and intimate connection between spindle orientation and endothelial cell division and polarization, spindle orientation during mitosis is essential to blood vessel development, so, when abnormal, the proteins and processes related to abnormal spindle orientation might be expected to participate in vascular development diseases (Zhong and Zhou, 2017; Figure 1). In this review, we summarize how spindle orientation regulates endothelial cell division to affect vascular development and discuss the relationship between misorientation and pathological state.

\section{BLOOD VESSEL DEVELOPMENT}

Oxygen and nutrient transport in developing embryos depends on the formation of vascular networks (Ma and Zhou, 2020), and many pathologies involve blood vessel development and remodeling (Potente et al., 2011). Each organ in the human body has its own capillary bed with both general and specific functions to respond to dynamic systemic and local changes (Augustin and Koh, 2017). Blood vessel development includes vasculogenesis and angiogenesis. Vasculogenesis, the formation of embryonic blood vessels, involves the differentiation, migration, and coalescence of angioblasts and the polarization of endothelial cells to form a vascular lumen and create a primordial vascular network. During angiogenesis, new blood vessels are formed from existing capillaries or venules by endothelial cell proliferation, differentiation, and migration (Carmeliet and Jain, 2011). When endothelial cells form sprouts, two distinct phenotypes are undertaken by the endothelial cells asymmetric division in the nascent blood vessel sprout, namely the tip cell phenotype and the stalk cell phenotype (Koon et al., 2018). Tip cells bring about motile behavior which migrate toward the angiogenic source upon stimulation by chemotactic factors. Stalk cells trail behind the tip cells to support the growth of the vessel by their proliferative capacity (Gerhardt et al., 2003; Figure 1B). In addition, stalk cells ensure stability and integrity of the young sprout by forming adherent and tight junctions (Blanco and Gerhardt, 2013). Therefore, its dysfunction can cause inflammatory, infectious and immune disorders (Carmeliet, 2003). Furthermore, polarized positioning of the mitotic spindle functions to generate intrinsically asymmetric daughters of tip cell division, which is essential for vessel sprout formation. Many aspects in tissue morphogenesis are attributed to a collective behavior of the participating cells (Lv et al., 2020). Daughters of tip cell rapidly selforganize into leading and trailing cells following division, which maintains uninterrupted collective migration during vessel proliferation (Costa et al., 2016). During vascular development, endothelial cell migration, proliferation, polarity, differentiation, and intercellular communication must be tightly coordinated for functional vascular morphogenesis (Herbert and Stainier, 2011). Blood vessel development plays an important role in vascular barrier formation (Tam and Watts, 2010), tumorigenesis (Yadav et al., 2015), and ischemic, inflammatory, infectious, and immune disorders (Carmeliet, 2003).

\section{THE ROLE OF SPINDLE ORIENTATION IN BLOOD VESSEL DEVELOPMENT}

The correct separation of chromosomes into daughter cells of different sizes or cell fates requires precise spindle orientation to control cell fate choices, tissue architecture, and tissue morphogenesis (Morin and Bellaïche, 2011; di Pietro et al., 2016; Chen et al., 2020). Blood vessel development depends on vascular lumen formation, which requires the precise mitotic spindle orientation of endothelial cells and the establishment of polarity to form opposed apical cell surfaces (Neufeld et al., 2014). Endothelial cleavage plane oriented perpendicular to the blood vessel long axis would effectively lengthen the blood vessel, whereas divisions oriented parallel to the blood vessel long axis would effectively increase the blood vessel diameter (Figure 1A). In particular, during angiogenesis, the asymmetric division of endothelial tip cells generates heterogeneous daughter cells that maintain hierarchical tip-stalk organization and synchronize collective movements (Costa et al., 2016). These processes are closely related to mitotic spindle orientation, which is precisely controlled by many cues, either intrinsic or extrinsic, such as natural direct current electric fields (DC-EFs) and many signaling pathways and proteins that play an important role in spindle orientation including VEGF signaling, the Rho family of GTPases Cdc42 are also indispensable to vascular development and regeneration. Highlighting its importance in blood vessel development, the aberrant regulation of spindle orientation has been linked to a variety of human diseases.

\section{VEGF Signaling}

Among the already identified pro-angiogenic molecules, vascular endothelial growth factor (VEGF) is established as the key angiogenic growth factor (Melincovici et al., 2018; Li S. et al., 2019), by regulating blood vessel growth and maintenance. Pioneering studies showed that VEGF signaling affects vascular morphogenesis by controlling the orientation of endothelial cell division perpendicular to the vessel long axis (Zeng et al., 2007). It is reported that this process is affected by a number of factors. First, oriented endothelial divisions appear to be associated with VEGF but is independent of blood flow during early development (Bautch, 2012). Blood vessels derived from embryonic stem cells do not undergo flow-directed endothelial cell division, whose plane of division is perpendicular to the long axis of the vessel, and retinal vessels near the vascular front that likely have low shear stress also orient endothelial divisions (Zeng et al., 2007). Within the vascularized retina, by binding to VEGFR2, VEGF alters the orientation of endothelial cell cleavage planes during anaphase in the major veins and arterioles to further increase vessel tortuosity and dilation independent of eNOS (Hartnett et al., 2008). Therefore, eNOS does not appear to be essential in VEGF-mediated orientation of endothelial cell division. 


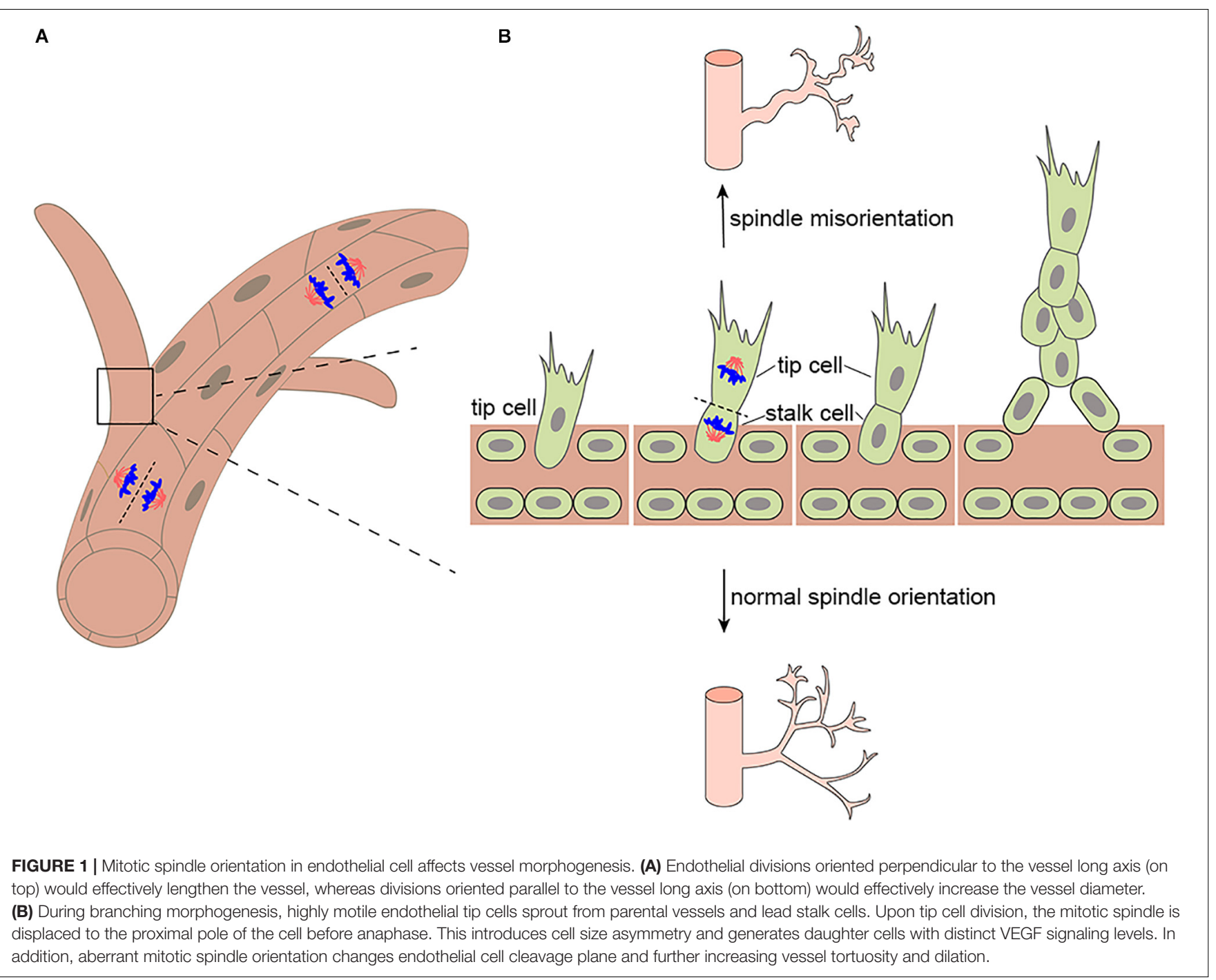

In the process of forming new blood vessel branches through angiogenesis, endothelial tip cells, which lead nascent vessels (Herbert and Stainier, 2011), likely underpin asymmetric cell division by asymmetric positioning of the mitotic spindle to form asymmetries in cell size and VEGFR signaling components during anaphase (Costa et al., 2017). In this way, the formation of the leading tip and trailing stalk endothelial cells is precisely regulated. Importantly, asymmetries in VEGF signaling following division have been shown to be essential for normal vessel formation by instantly re-establishing the tip-stalk hierarchy and maintaining uninterrupted collective migration during proliferative growth (Costa et al., 2016). Costa et al., confirmed that the larger distal daughter of tip cell division inherited a greater proportion of the VEGF signaling machinery and displayed higher levels of VEGF signaling, establishing it as the leading tip cell. In the absence of differential VEGFR activity the tip-stalk arrangement of daughters was disrupted and cells display symmetric motilities (Costa et al., 2016). We can guess this may explain why abnormal vascular patterns develop in some pathological angiogenesis. Furthermore, in a model of human retinopathy of prematurity (ROP), endothelial NADPH oxidase 4 regulated VEGF receptor (VEGFR)2-mediated angiogenesis and intravitreal neovascularization through activated STAT3 (Wang et al., 2014). However, whether this process further influences angiogenesis by influencing spindle orientation is not clear.

\section{Natural Direct Current Electric Fields (DC-EFs)}

Endogenous electric fields, which have been measured directly in animals and in humans, are ubiquitous and may play a significant role in development (McCaig and Zhao, 1997). Electrical stimulation has emerged as a novel approach to induce angiogenesis in vivo, and this process is regulated through increased expression of VEGF in muscle cells (Cuevas and AsinCardiel, 2000). DC EFs of $200 \mathrm{mV} / \mathrm{mm}$ increased secretion of vascular endothelial growth factor (VEGF) and interleukin 8 (IL-8) in starved HUVEC cells (Zhao et al., 2004; Bai et al., 2011). It has been proved that electric fields of 150$400 \mathrm{mV} / \mathrm{mm}$ induced reorientation of the long axis of the 


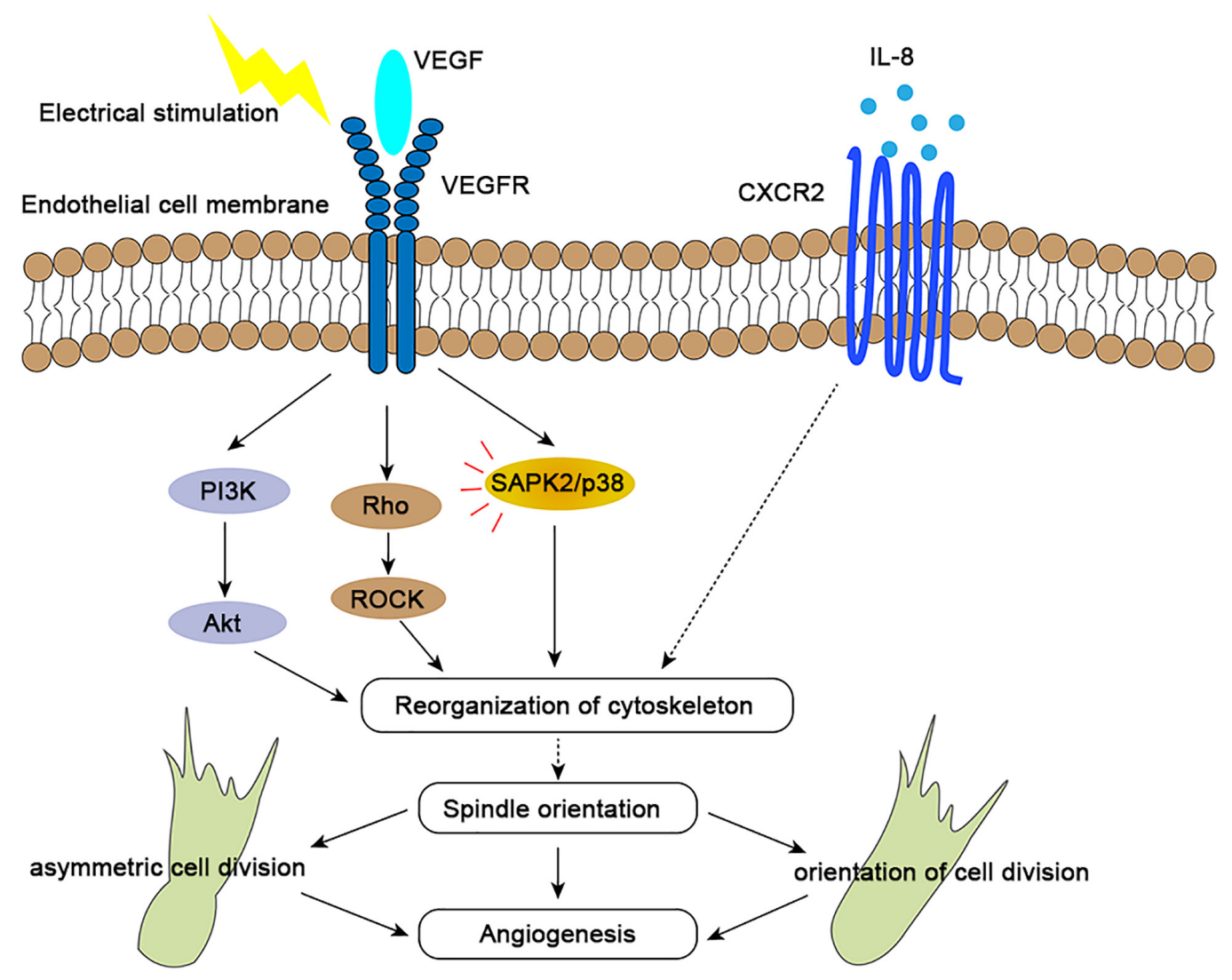

FIGURE 2 | Molecular mechanisms of spindle orientation effects in angiogenesis. By binding to VEGFR2, VEGF activates the PI3K/Akt, Rho/ROCK, and SAPK/p38 signaling pathways (red lines), which results in precise orientation of the mitotic spindle, endothelial cell asymmetry and orientation, and consequent directional angiogenesis. Interleukin-8 (IL-8) binds with high affinity to the chemokine receptor CXCR2, which may also regulate spindle orientation by influencing reorganization of cytoskeleton to further affect spindle orientation, further impacting angiogenesis. Both receptors and signaling pathways are upregulated upon electrical stimulation.

endothelial cells perpendicular to the EF vector (Zhao et al., 2004; Cunha et al., 2019). This process were mediated by VEGFR activation, with downstream Rho-ROCK and PI3KAkt activation leading to cytoskeletal reorganization and the mitotic spindle orientation (Zhao et al., 2004; Figure 2). Electric fields also upregulate the expression of the chemokine receptors CXCR4 and CXCR2 (Cunha et al., 2019). Interleukin 8 (IL-8) with high-affinity binding to the CXCR2 chemokine receptors may stimulate endothelial cell proliferation (Holmes et al., 1991; Baggiolini et al., 1997; Leclair et al., 2014). However, how these chemokines affect orientation of endothelial cell division is still unclear (Figure 2). In general, electrical stimulation may play a spatial organization role in angiogenesis by regulating the endothelial mitotic spindle orientation (Bai et al., 2004).

\section{G-Protein-Signaling Modulator 2 (GPSM-2 or LGN)}

Proper mitotic spindle orientation requires that astral microtubules are connected to the cell cortex by the microtubulebinding protein NuMA. Its cortical recruitment is mediated via direct binding to the adaptor protein LGN which participates in MT-orienting complexes to further regulate mitotic spindle orientation (Yang et al., 2014; Takayanagi et al., 2019). In many cell types, mitotic spindle orientation relies on the canonical "LGN complex" composed of Pins/LGN, Mud/NuMA, and Gai subunits, which is evolutionary conserved in Drosophila and vertebrates (Saadaoui et al., 2017; Kschonsak and Hoffmann, 2018). In vertebrates, the Gai-LGN-NuMA complex anchors astral microtubules and orients spindles to regulate asymmetric divisions (Zhu et al., 2011). However, although LGN knockdown perturbs overall endothelial sprouting, spindle orientation in sprouting endothelial cells do not require LGNLGN instead influences interphase microtubule dynamics in endothelial cells to regulate migration, cell adhesion, and sprout extension (Wright et al., 2015). So the potential role of LGN in the blood vessel development may be focused on cell migration and adhesion. In addition, these data might also indicate that different mechanisms regulate spindle orientation in vascular endothelial cells and other cells, and this requires further study. At the same time, there may be novel pathway contributing to spindle orientation during blood vessel formation and therefore possible new therapeutic targets need to be discovered. 


\section{The Rho Family of GTPases: Cdc42}

Cdc42, a small GTPase, controls spindle orientation during cell division to regulate epithelial morphogenesis and repair (Jaffe et al., 2008; Mitsushima et al., 2009; Xia et al., 2015). With regards to the development of blood vessels, Cdc42 is essential in embryonic development and a vital regulator of endothelial cell development, regulating actin-based morphogenesis and cell polarity. An absence of Cdc42 results in embryonic death through angiogenesis defects (Jin et al., 2013; Barry et al., 2015). Cdc42 also plays an important role in endothelial regeneration and vascular repair (Flentje et al., 2019). Endothelial cell regeneration is important in the resolution of inflammation and the restoration of vascular integrity after inflammatory vascular injury (Zhao et al., 2014). Cdc42 was shown to affect endothelial cell proliferation through the PAK1/Akt pathway to further regulate vascular recovery after inflammatory lung injury (Lv et al., 2018).

Cdc42 is also involved in sphingosine-1-phosphate (S1P) signal transduction to enhance the barrier function of endothelial monolayers, which can promote vascular stability (Reinhard et al., 2017). It has also been proposed that an absence of Cdc42 leads to defective endothelial axial polarization, sparing endothelial cell proliferation but preventing them from precisely re-distributing within the vascular network and resulting in severe vascular malformations as a consequence of defective cell migration (Laviña et al., 2018). Whether mitotic spindle orientation is of relevance for vascular malformations remains to be further elucidated.

\section{SPINDLE MISORIENTATION IS ASSOCIATED WITH DISEASES}

The orientation of the cell division axis determines the positions of daughter cells in a tissue and is therefore crucial to tissue morphogenesis and cell fate decisions (Théry and Bornens, 2006; di Pietro et al., 2016; Chen et al., 2019). Recent studies have shown that a number of factors can regulate the orientation of mitotic spindles and therefore cell division orientation (Li J. et al., 2019). As is stated above, intrinsic factor VEGF signaling and extrinsic factor electric fields (EFs) play an important role in affecting the mitotic spindle orientation to regulate the blood vessel development. An increasing number of vascular development disorders have been reported to result from spindle orientation defects.

Firstly, human retinopathy of prematurity (ROP) has been linked to altered spindle orientation. aberrant mitotic spindle orientation causes ROP by changing endothelial cell cleavage plane and further increasing vessel tortuosity and dilation (Hartnett et al., 2008; Figure 1B). Secondly, diabetic retinopathy (DR), the most common microvascular complication of diabetes maybe also be associated with spindle misorientation. VEGF is overexpressed in hyperglycemic environments and is upregulated by tissue hypoxia, which increases vessel tortuosity and dilation by altering the orientation of endothelial cell cleavage planes during anaphase in the major veins and arterioles within the vascularized retina (Figure 1B; Hartnett et al., 2008; Capitão and Soares, 2016). Moreover, blood vessels provide nutrients and oxygen to tumors, and insufficient or abnormal angiogenesis contributes to tumor survival, invasion, and metastasis (Saman et al., 2020). In addition to providing nutrients and oxygen to the tumor and the removal of metabolic waste, new vessel formation also enables cancer cells to metastasize and proliferate to distant sites through entry into the newly formed blood and lymphatic system and subsequent extravasation (Nishida et al., 2006). Thus, spindle orientation in the tumor vasculature has become a new key anti-tumor therapeutic target. It is imperative that future studies determine in which of these diseases spindle misorientation contributes to pathogenesis. Beyond that, the mechanisms that prevent spindle misorientation need to be uncovered.

\section{CONCLUSION AND PERSPECTIVES}

Cell division orientation plays an essential role in tissue morphogenesis and cell fate decisions. This is achieved through the formation of the mitotic spindle ( $\mathrm{Lu}$ and Johnston, 2013). The VEGF/VEGFR signaling pathways is key regulator of spindle orientation during angiogenesis (Hartnett et al., 2008), which controlling the orientation of endothelial cell division perpendicular to the vessel long axis to further affect vascular morphogenesis (Zeng et al., 2007). At the same time, IL-8/CXCR2 signaling pathway also was activated during electric fields exposure. Therefore, there has been a hypothetical mechanism that VEGF induces CXCR2 production by endothelial cells, creating a positive-feedback loop to influence spindle orientation (Cunha et al., 2019). Although many of the mechanisms by which planar spindle orientation are tightly regulated and the roles of mitotic spindle orientation in epithelial development and disease have been well studied (di Pietro et al., 2016), further research is needed to see the details of the underlying mechanisms of how spindle orientation affects vascular development by regulating endothelial cell orientation. The differences between the epithelium and endothelium are important to take into consideration. For example, some spindle orientation-related proteins playing important roles in epithelia, such as LGN, did not affect the oriented division of endothelial cell (Wright et al., 2015). Consequently, further studies of the basic molecular mechanisms of how spindle orientation in endothelial cells influences angiogenesis are required, not least to identify potential therapeutic targets. A key challenge will be to determine the precise in vivo mechanism of plane spindle orientation and its involvement in blood vessel development.

Aberrant spindle orientation is hypothesized to contribute to tissue disorganization (Qin et al., 2017; Xie et al., 2019). Targeted anti-VEGF therapies have been widely researched, but they cause various side-effects such as hypertension, and are susceptible to drug resistance (Bergers and Hanahan, 2008). Advances in electrical stimulation and an improved understanding of the biological effects of stimulation might lead to new therapies to enhance blood vessel repair and regeneration and to treat diseases or conditions in which angiogenesis is part of the pathogenesis (Cunha et al., 2019). ES has been widely used to induce 
neurogenic and cardiomyogenic regeneration (Ragnarsson, 2008; Zhang et al., 2011) through regulating endothelial cell migration to wound site (Jeong et al., 2017) and affecting endothelial cell division orientation via VEGF signaling (Zhao et al., 2004). However, spindle orientation proteins have yet to be targeted directly in endothelial cell therapy, and further work is required to establish how mitotic spindles control the orientation and asymmetry of endothelial cells during angiogenesis to leverage the process for the treatment of vascular developmentrelated diseases. Overall, investigation of the role of spindle misorientation in diseases is just beginning, and the most intriguing questions remain to be addressed.

\section{REFERENCES}

Apte, R. S., Chen, D. S., and Ferrara, N. (2019). VEGF in signaling and disease: beyond discovery and development. Cell 176, 1248-1264. doi: 10.1016/j.cell. 2019.01.021

Augustin, H. G., and Koh, G. Y. (2017). Organotypic vasculature: from descriptive heterogeneity to functional pathophysiology. Science 357:6353.

Baggiolini, M., Dewald, B., and Moser, B. (1997). Human chemokines: an update. Annu. Rev. Immunol. 15, 675-705. doi: 10.1146/annurev.immunol.15.1.675

Bai, H., Forrester, J. V., and Zhao, M. (2011). DC electric stimulation upregulates angiogenic factors in endothelial cells through activation of VEGF receptors. Cytokine 55, 110-115. doi: 10.1016/j.cyto.2011.03.003

Bai, H., McCaig, C. D., Forrester, J. V., and Zhao, M. (2004). DC electric fields induce distinct preangiogenic responses in microvascular and macrovascular cells. Arterioscler. Thromb. Vasc. Biol. 24, 1234-1239. doi: 10.1161/01.atv. 0000131265.76828.8a

Barry, D. M., Xu, K., Meadows, S. M., Zheng, Y., Norden, P. R., Davis, G. E., et al. (2015). Cdc42 is required for cytoskeletal support of endothelial cell adhesion during blood vessel formation in mice. Development 142, 3058-3070. doi: $10.1242 /$ dev.125260

Bautch, V. L. (2012). VEGF-directed blood vessel patterning: from cells to organism. Cold Spring Harb. Perspect. Med. 2:a006452. doi: 10.1101/ cshperspect.a006452

Bergers, G., and Hanahan, D. (2008). Modes of resistance to anti-angiogenic therapy. Nat. Rev. Cancer 8, 592-603. doi: 10.1038/nrc2442

Blanco, R., and Gerhardt, H. (2013). VEGF and Notch in tip and stalk cell selection. Cold Spring Harb. Perspect. Med. 3:a006569. doi: 10.1101/cshperspect.a006569

Capitão, M., and Soares, R. (2016). Angiogenesis and inflammation crosstalk in diabetic retinopathy. J. Cell. Biochem. 117, 2443-2453. doi: 10.1002/jcb. 25575

Carmeliet, P. (2000). Mechanisms of angiogenesis and arteriogenesis. Nat. Med. 6, 389-395. doi: 10.1038/74651

Carmeliet, P. (2003). Angiogenesis in health and disease. Nat. Med. 9, 653-660.

Carmeliet, P., and Jain, R. K. (2011). Molecular mechanisms and clinical applications of angiogenesis. Nature 473, 298-307. doi: 10.1038/nature10144

Chen, M., Cao, Y., Dong, D., Zhang, Z., Zhang, Y., Chen, J., et al. (2019). Regulation of mitotic spindle orientation by phosphorylation of end binding protein 1. Exp. Cell Res. 384, 111618. doi: 10.1016/j.yexcr.2019.111618

Chen, M., Wang, J., Yang, Y., Zhong, T., Zhou, P., Ma, H., et al. (2020). Redoxdependent regulation of end-binding protein 1 activity by glutathionylation. Sci. China Life Sci.

Costa, G., Harrington, K. I, Lovegrove, H. E., Page, D. J., Chakravartula, S., Bentley, K., et al. (2016). Asymmetric division coordinates collective cell migration in angiogenesis. Nat. Cell Biol. 18, 1292-1301. doi: 10.1038/ncb3443

Costa, G., Lovegrove, H. E., and Herbert, S. P. (2017). Endothelial cells divide unequally to sprout fairly. Cell Cycle 16, 595-596. doi: 10.1080/15384101.2017. 1294942

Cuevas, P., and Asin-Cardiel, E. (2000). Electromagnetic therapeutic angiogenesis: the next step. Neurol. Res. 22, 349-350. doi: 10.1080/01616412.2000.11740682

Cunha, F., Rajnicek, A. M., and McCaig, C. D. (2019). Electrical stimulation directs migration, enhances and orients cell division and upregulates the chemokine

\section{AUTHOR CONTRIBUTIONS}

$\mathrm{XW}$ wrote the manuscript and drew the figures. JZ revised the manuscript. DL conceived the study and edited the manuscript. All authors contributed to the article and approved the submitted version.

\section{FUNDING}

This work was supported by a grant from the National Natural Science Foundation of China (31771542 and 31871347).

receptors CXCR4 and CXCR2 in endothelial cells. J. Vasc. Res. 56, 39-53. doi: 10.1159/000495311

di Pietro, F., Echard, A., and Morin, X. (2016). Regulation of mitotic spindle orientation: an integrated view. EMBO Rep. 17, 1106-1130. doi: 10.15252/ embr.201642292

Flentje, A., Kalsi, R., and Monahan, T. S. (2019). Small GTPases and their role in vascular disease. Int. J. Mol. Sci. 20:917. doi: 10.3390/ijms20040917

Gerhardt, H., Golding, M., Fruttiger, M., Ruhrberg, C., Lundkvist, A., Abramsson, A., et al. (2003). VEGF guides angiogenic sprouting utilizing endothelial tip cell filopodia. J. Cell Biol. 161, 1163-1177. doi: 10.1083/jcb.200302047

Hartnett, M. E., Martiniuk, D., Byfield, G., Geisen, P., Zeng, G., and Bautch, V. L. (2008). Neutralizing VEGF decreases tortuosity and alters endothelial cell division orientation in arterioles and veins in a rat model of ROP: relevance to plus disease. Invest. Ophthalmol. Vis. Sci. 49, 3107-3114. doi: 10.1167/iovs.081780

Herbert, S. P., and Stainier, D. Y. (2011). Molecular control of endothelial cell behaviour during blood vessel morphogenesis. Nat. Rev. Mol. Cell Biol. 12, 551-564. doi: 10.1038/nrm3176

Hogan, B. M., and Schulte-Merker, S. (2017). How to plumb a pisces: understanding vascular development and disease using zebrafish embryos. Dev. Cell 42, 567-583. doi: 10.1016/j.devcel.2017.08.015

Holmes, W. E., Lee, J., Kuang, W. J., Rice, G. C., and Wood, W. I. (1991). Structure and functional expression of a human interleukin-8 receptor. Science 253, 1278-1280.

Jaffe, A. B., Kaji, N., Durgan, J., and Hall, A. (2008). Cdc42 controls spindle orientation to position the apical surface during epithelial morphogenesis. J. Cell Biol. 183, 625-633. doi: 10.1083/jcb.200807121

Jeong, G. J., Oh, J. Y., Kim, Y. J., Bhang, S. H., Jang, H. K., Han, J., et al. (2017). Therapeutic angiogenesis via solar cell-facilitated electrical stimulation. ACS Appl. Mater. Interfaces 9, 38344-38355. doi: 10.1021/acsami.7b13322

Jin, Y., Liu, Y., Lin, Q., Li, J., Druso, J. E., Antonyak, M. A., et al. (2013). Deletion of Cdc42 enhances ADAM17-mediated vascular endothelial growth factor receptor 2 shedding and impairs vascular endothelial cell survival and vasculogenesis. Mol. Cell. Biol. 33, 4181-4197. doi: 10.1128/mcb.00650-13

Koon, Y. L., Zhang, S., Rahmat, M. B., Koh, C. G., and Chiam, K. H. (2018). Enhanced delta-notch lateral inhibition model incorporating intracellular notch heterogeneity and tension-dependent rate of delta-notch binding that reproduces sprouting angiogenesis patterns. Sci. Rep. 8:9519.

Kschonsak, Y. T., and Hoffmann, I. (2018). Activated ezrin controls MISP levels to ensure correct NuMA polarization and spindle orientation. J. Cell Sci. 131:jcs214544. doi: 10.1242/jcs.214544

Laviña, B., Castro, M., Niaudet, C., Cruys, B., Álvarez-Aznar, A., Carmeliet, P., et al. (2018). Defective endothelial cell migration in the absence of Cdc42 leads to capillary-venous malformations. Development 145:dev161182. doi: 10.1242/ dev.161182

Leclair, H. M., Dubois, S. M., Azzi, S., Dwyer, J., Bidère, N., and Gavard, J. (2014). Control of CXCR2 activity through its ubiquitination on $\mathrm{K} 327$ residue. BMC Cell Biol. 15:38. doi: 10.1186/s12860-014-0038-0

Li, J., Cheng, L., and Jiang, H. (2019). Cell shape and intercellular adhesion regulate mitotic spindle orientation. Mol. Biol. Cell 30, 2458-2468. doi: 10.1091/mbc. e19-04-0227 
Li, S., Xu, H. X., Wu, C. T., Wang, W. Q., Jin, W., Gao, H. L., et al. (2019). Angiogenesis in pancreatic cancer: current research status and clinical implications. Angiogenesis 22, 15-36. doi: 10.1007/s10456-018-9645-2

Liro, M. J., and Rose, L. S. (2016). Mitotic spindle positioning in the EMS cell of Caenorhabditis elegans requires LET-99 and LIN-5/NuMA. Genetics 204, 1177-1189. doi: 10.1534/genetics.116.192831

$\mathrm{Lu}, \mathrm{M}$. S., and Johnston, C. A. (2013). Molecular pathways regulating mitotic spindle orientation in animal cells. Development 140, 1843-1856. doi: 10.1242/ dev. 087627

Luo, Y., Ran, J., Xie, S., Yang, Y., Chen, J., Li, S., et al. (2016). ASK1 controls spindle orientation and positioning by phosphorylating EB1 and stabilizing astral microtubules. Cell Discov. 2:16033.

Lv, J., Zeng, J., Guo, F., Li, Y., Xu, M., Cheng, Y., et al. (2018). Endothelial $\mathrm{Cdc} 42$ deficiency impairs endothelial regeneration and vascular repair after inflammatory vascular injury. Respir. Res. 19:27.

Lv, Z., Rosenbaum, J., Mohr, S., Zhang, X., Kong, D., Preiss, H., et al. (2020). The emergent yo-yo movement of nuclei driven by cytoskeletal remodeling in pseudo-synchronous mitotic cycles. Curr. Biol. 30, 2564.e5-2573.e5.

Ma, N., and Zhou, J. (2020). Functions of endothelial cilia in the regulation of vascular barriers. Front. Cell Dev. Biol. 8:626. doi: 10.3389/fcell.2020.00626

McCaig, C. D., and Zhao, M. (1997). Physiological electrical fields modify cell behaviour. Bioessays 19, 819-826. doi: 10.1002/bies.950190912

Melincovici, C. S., Boşca, A. B., Şuşman, S., Mărginean, M., Mihu, C., Istrate, M., et al. (2018). Vascular endothelial growth factor. (VEGF) - key factor in normal and pathological angiogenesis. Rom. J. Morphol. Embryol. 59, 455-467.

Mitsushima, M., Toyoshima, F., and Nishida, E. (2009). Dual role of Cdc42 in spindle orientation control of adherent cells. Mol. Cell. Biol. 29, 2816-2827. doi: $10.1128 / \mathrm{mcb} .01713-08$

Morin, X., and Bellaïche, Y. (2011). Mitotic spindle orientation in asymmetric and symmetric cell divisions during animal development. Dev. Cell 21, 102-119. doi: 10.1016/j.devcel.2011.06.012

Nakajima, Y. I. (2018). Mitotic spindle orientation in epithelial homeostasis and plasticity. J. Biochem. 164, 277-284.

Neufeld, S., Planas-Paz, L., and Lammert, E. (2014). Blood and lymphatic vascular tube formation in mouse. Semin. Cell Dev. Biol. 31, 115-123. doi: 10.1016/j. semcdb.2014.02.013

Nishida, N., Yano, H., Nishida, T., Kamura, T., and Kojiro, M. (2006). Angiogenesis in cancer. Vasc. Health Risk Manag. 2, 213-219.

Potente, M., Gerhardt, H., and Carmeliet, P. (2011). Basic and therapeutic aspects of angiogenesis. Cell 146, 873-887. doi: 10.1016/j.cell.2011.08.039

Qin, J., Yang, Y., Gao, S., Liu, Y., Yu, F., Zhou, Y., et al. (2017). Deregulated ALG2/HEBP2 axis alters microtubule dynamics and mitotic spindle behavior to stimulate cancer development. J. Cell. Physiol. 232, 3067-3076. doi: 10.1002/ jcp. 25754

Ragnarsson, K. T. (2008). Functional electrical stimulation after spinal cord injury: current use, therapeutic effects and future directions. Spinal Cord 46, 255-274. doi: 10.1038/sj.sc.3102091

Reinhard, N. R., Mastop, M., Yin, T., Wu, Y., Bosma, E. K., Gadella, T. W. J. Jr., et al. (2017). The balance between $\mathrm{G} \alpha(\mathrm{i})-\mathrm{Cdc} 42 / \mathrm{Rac}$ and $\mathrm{G} \alpha(1)(2) /(1)(3)-$ RhoA pathways determines endothelial barrier regulation by sphingosine-1phosphate. Mol. Biol. Cell 28, 3371-3382. doi: 10.1091/mbc.e17-03-0136

Saadaoui, M., Konno, D., Loulier, K., Goiame, R., Jadhav, V., Mapelli, M., et al. (2017). Loss of the canonical spindle orientation function in the Pins/LGN homolog AGS3. EMBO Rep. 18, 1509-1520. doi: 10.15252/embr.2016 43048

Sajib, S., Zahra, F. T., Lionakis, M. S., German, N. A., and Mikelis, C. M. (2018). Mechanisms of angiogenesis in microbe-regulated inflammatory and neoplastic conditions. Angiogenesis 21, 1-14. doi: 10.1007/s10456-017-9583-4

Saman, H., Raza, S. S., Uddin, S., and Rasul, K. (2020). Inducing angiogenesis, a key step in cancer vascularization, and treatment approaches. Cancers 12:1172. doi: $10.3390 /$ cancers 12051172

Takayanagi, H., Hayase, J., Kamakura, S., Miyano, K., Chishiki, K., Yuzawa, S., et al. (2019). Intramolecular interaction in LGN, an adaptor protein that regulates mitotic spindle orientation. J. Biol. Chem. 294, 19655-19666. doi: 10.1074/jbc. ra119.011457

Tam, S. J., and Watts, R. J. (2010). Connecting vascular and nervous system development: angiogenesis and the blood-brain barrier. Annu. Rev. Neurosci. 33, 379-408. doi: 10.1146/annurev-neuro-060909-152829
Théry, M., and Bornens, M. (2006). Cell shape and cell division. Curr. Opin. Cell Biol. 18, 648-657. doi: 10.1016/j.ceb.2006.10.001

Ting Song, J. Z. (2020). Primary cilia in corneal development and disease. Zool. Res. $41,495-502$.

Wang, H., Yang, Z., Jiang, Y., and Hartnett, M. E. (2014). Endothelial NADPH oxidase 4 mediates vascular endothelial growth factor receptor 2 -induced intravitreal neovascularization in a rat model of retinopathy of prematurity. Mol. Vis. 20, 231-241.

Wilkinson, R. N., and van Eeden, F. J. (2014). The zebrafish as a model of vascular development and disease. Prog. Mol. Biol. Transl. Sci. 124, 93-122. doi: 10.1016/ b978-0-12-386930-2.00005-7

Wright, C. E., Kushner, E. J., Du, Q., and Bautch, V. L. (2015). LGN directs interphase endothelial cell behavior via the microtubule network. PLoS One 10:e0138763. doi: 10.1371/journal.pone.0138763

Xia, J., Swiercz, J. M., Bañón-Rodríguez, I., Matkoviæ, I., Federico, G., Sun, T., et al. (2015). Semaphorin-plexin signaling controls mitotic spindle orientation during epithelial morphogenesis and repair. Dev. Cell. 33, 299-313. doi: 10. 1016/j.devcel.2015.02.001

Xie, S., Wu, Y., Hao, H., Li, J., Guo, S., Xie, W., et al. (2019). CYLD deficiency promotes pancreatic cancer development by causing mitotic defects. J. Cell. Physiol. 234, 9723-9732. doi: 10.1002/jcp.27658

Xie, W., Yang, Y., Gao, S., Song, T., Wu, Y., Li, D., et al. (2017). The tumor suppressor CYLD controls epithelial morphogenesis and homeostasis by regulating mitotic spindle behavior and adherens junction assembly. J. Genet. Genomics 44, 343-353. doi: 10.1016/j.jgg.2017.06.002

Xie, W., and Zhou, J. (2017). Regulation of mitotic spindle orientation during epidermal stratification. J. Cell. Physiol. 232, 1634-1639. doi: 10.1002/jcp.25750

Yadav, L., Puri, N., Rastogi, V., Satpute, P., and Sharma, V. (2015). Tumour angiogenesis and angiogenic inhibitors: a review. J. Clin. Diagn. Res. 9, Xe01$\mathrm{Xe} 05$.

Yang, Y., Liu, M., Li, D., Ran, J., Gao, J., Suo, S., et al. (2014). CYLD regulates spindle orientation by stabilizing astral microtubules and promoting dishevelledNuMA-dynein/dynactin complex formation. Proc. Natl. Acad. Sci. U.S.A. 111, 2158-2163. doi: 10.1073/pnas.1319341111

Zeng, G., Taylor, S. M., McColm, J. R., Kappas, N. C., Kearney, J. B., Williams, L. H., et al. (2007). Orientation of endothelial cell division is regulated by VEGF signaling during blood vessel formation. Blood 109, 1345-1352. doi: 10.1182/blood-2006-07-037952

Zhang, P., Liu, Z. T., He, G. X., Liu, J. P., and Feng, J. (2011). Low-voltage direct-current stimulation is safe and promotes angiogenesis in rabbits with myocardial infarction. Cell Biochem. Biophys. 59, 19-27. doi: 10.1007/s12013010-9107-y

Zhao, M., Bai, H., Wang, E., Forrester, J. V., and McCaig, C. D. (2004). Electrical stimulation directly induces pre-angiogenic responses in vascular endothelial cells by signaling through VEGF receptors. J. Cell Sci. 117(Pt 3), 397-405. doi: $10.1242 /$ jcs. 00868

Zhao, Y. D., Huang, X., Yi, F., Dai, Z., Qian, Z., Tiruppathi, C., et al. (2014). Endothelial FoxM1 mediates bone marrow progenitor cell-induced vascular repair and resolution of inflammation following inflammatory lung injury. Stem Cells 32, 1855-1864. doi: 10.1002/stem.1690

Zhong, T., and Zhou, J. (2017). Orientation of the mitotic spindle in the development of tubular organs. J. Cell. Biochem. 118, 1630-1633. doi: 10.1002/ jcb. 25865

Zhu, J., Wen, W., Zheng, Z., Shang, Y., Wei, Z., Xiao, Z., et al. (2011). LGN/mInsc and LGN/NuMA complex structures suggest distinct functions in asymmetric cell division for the Par3/mInsc/LGN and Gai/LGN/NuMA pathways. Mol. Cell. 43, 418-431. doi: 10.1016/j.molcel.2011.07.011

Conflict of Interest: The authors declare that the research was conducted in the absence of any commercial or financial relationships that could be construed as a potential conflict of interest.

Copyright (c) $2020 \mathrm{Wu}$, Zhou and Li. This is an open-access article distributed under the terms of the Creative Commons Attribution License (CC BY). The use, distribution or reproduction in other forums is permitted, provided the original author(s) and the copyright owner(s) are credited and that the original publication in this journal is cited, in accordance with accepted academic practice. No use, distribution or reproduction is permitted which does not comply with these terms. 